\title{
REPORT OF THE TREASURER FOR THE YEAR 1922
}

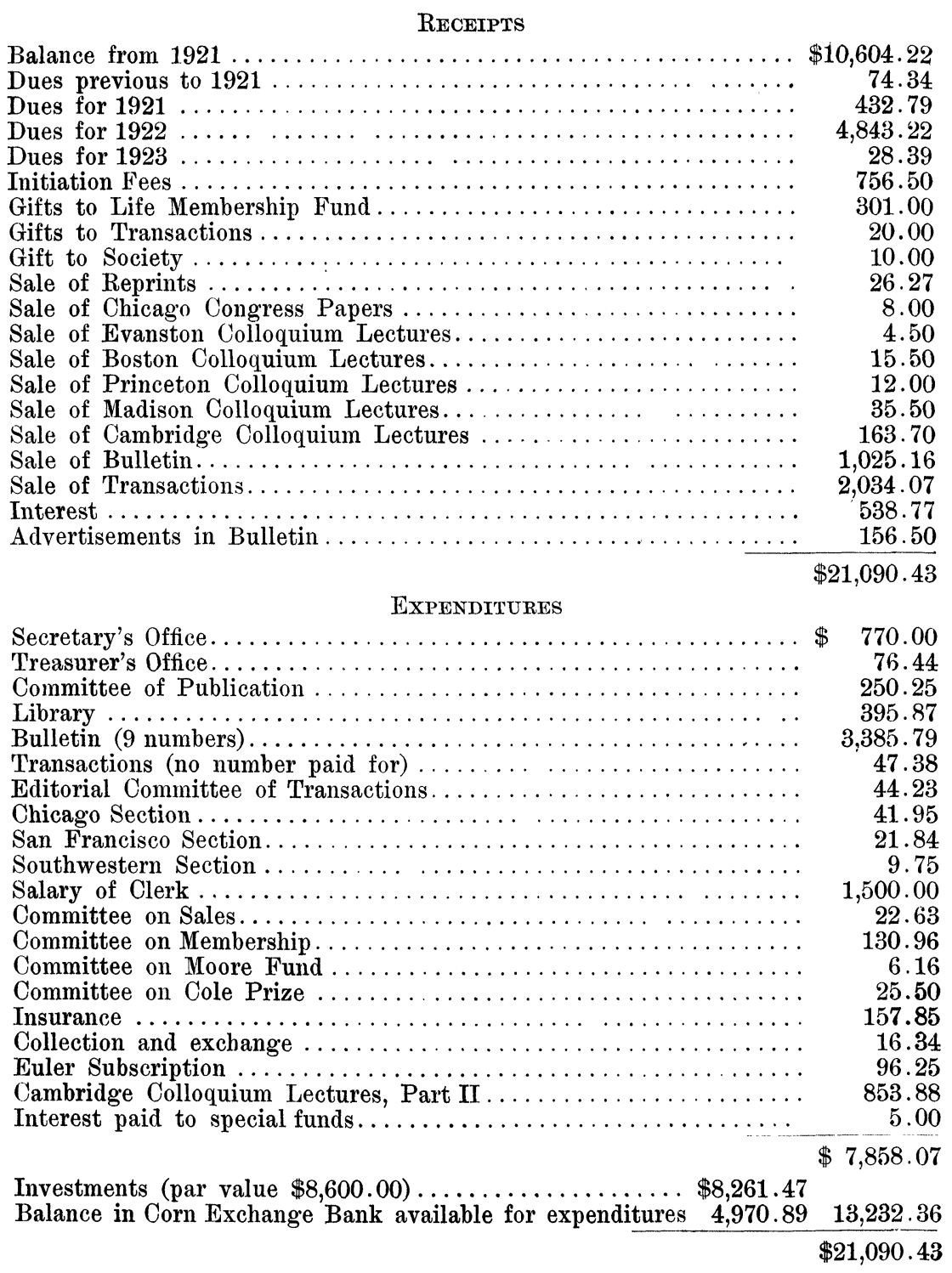

The reserve necessary to secure the Life Memberships is now $\$ 5,782.85$.

W. Benjamin Fite,

Treasurer.

New York, N. Y., December 20, 1922. 